\title{
Analysis of Topics Raised
}

The graphs that follow show what topics were raised in the three-hour interactive dialogue for each Commonwealth state that appeared in Geneva for the UPR. They are presented here in the chronological order in which the countries appeared in Geneva for the UPR session. They show how many times each topic was raised in a comment or question by Commonwealth and non-Commonwealth states. One comment may raise several issues and thus the totals in the graphs may be more than the questions or comments put to each state.

\section{Graph 1. United Kingdom}

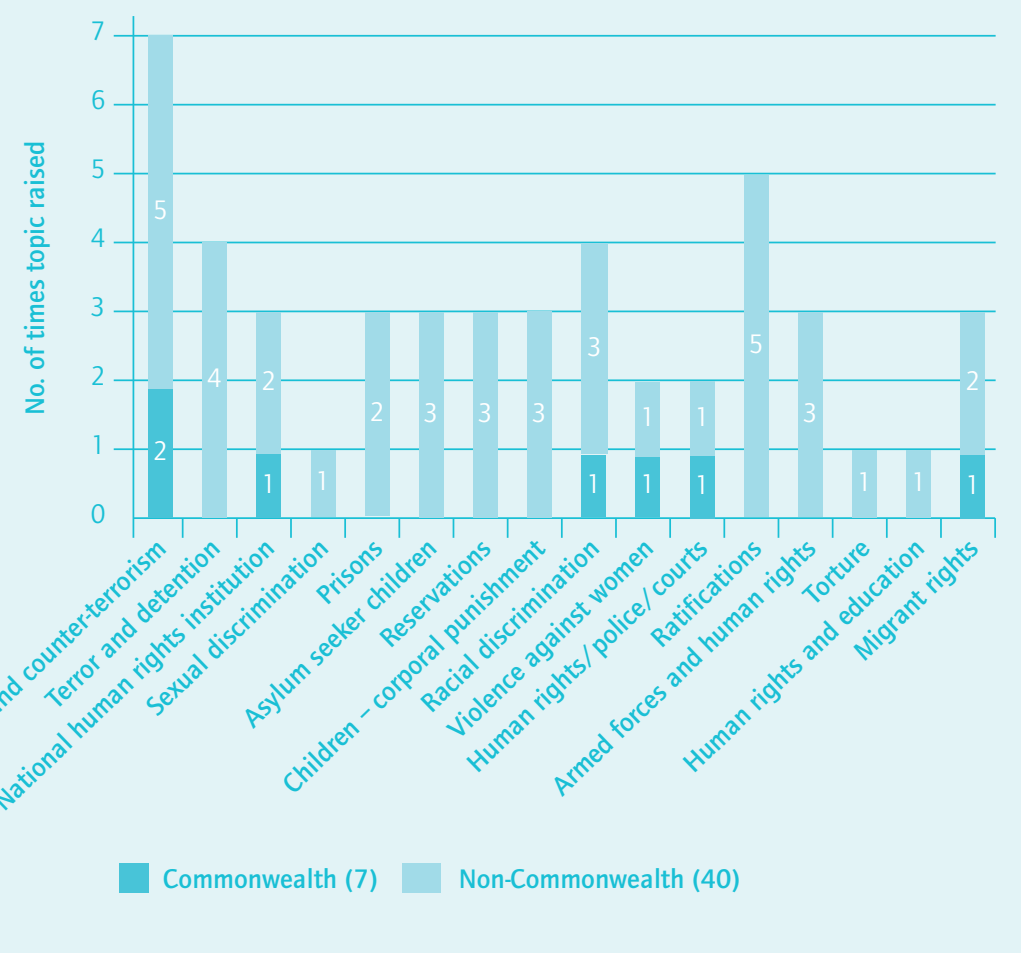


Graph 2. India

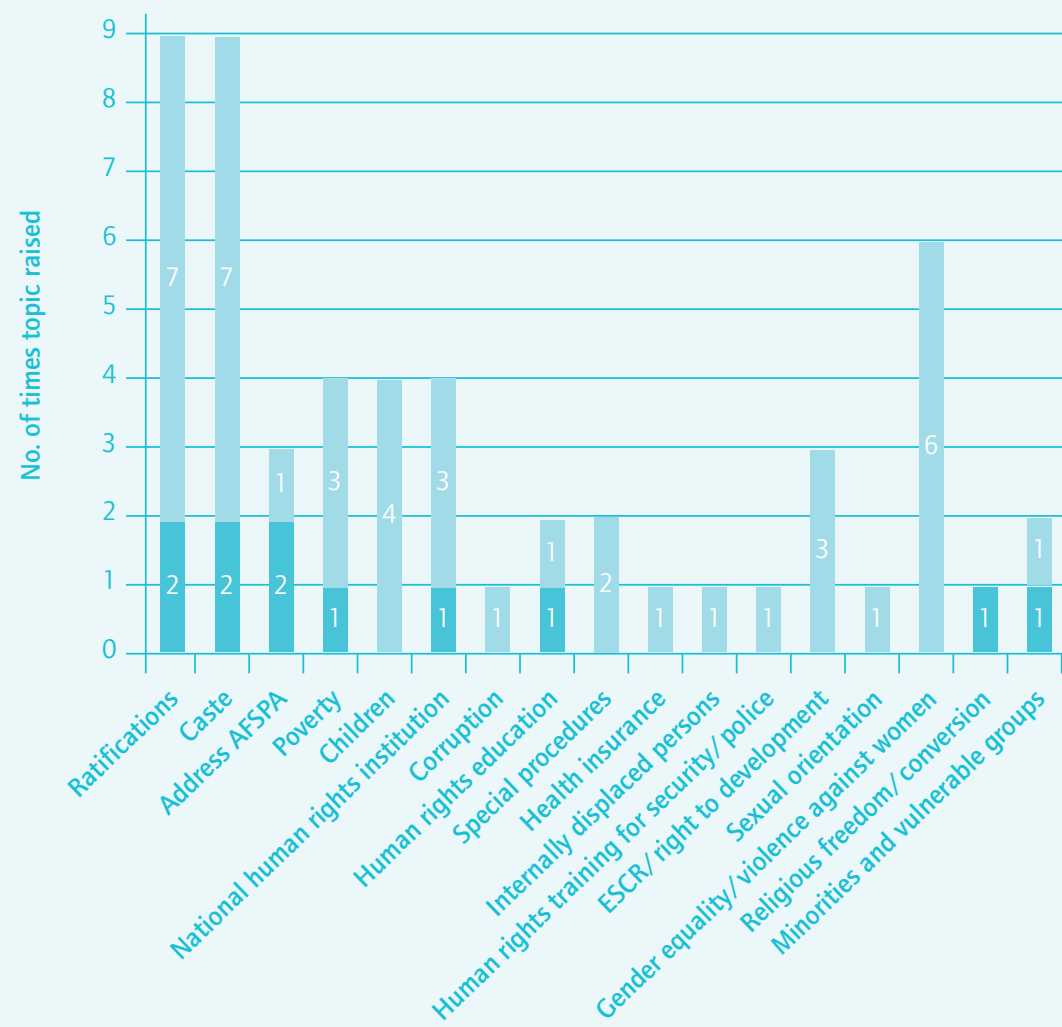

Commonwealth (11) Non-Commonwealth (44) 


\section{Graph 3. South Africa}

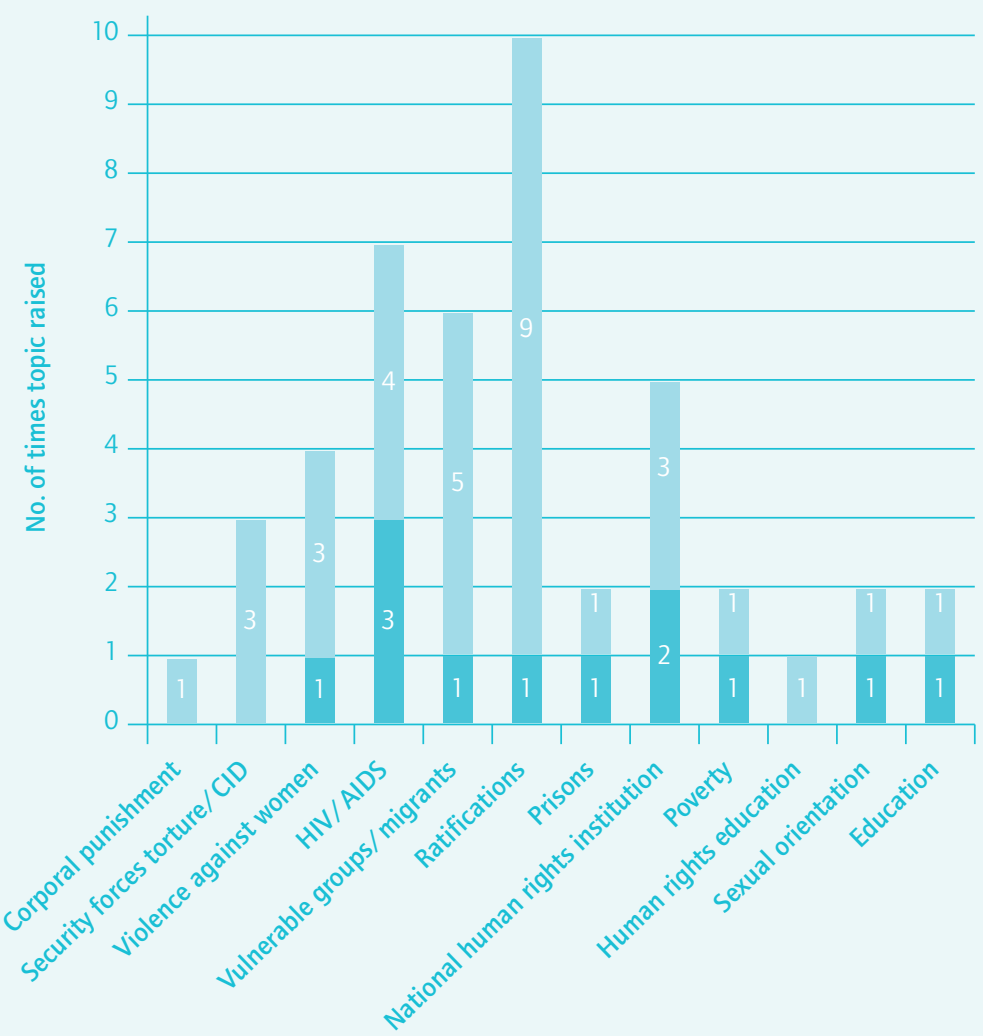

Commonwealth (12) Non-Commonwealth (33) 


\section{Graph 4. Ghana}

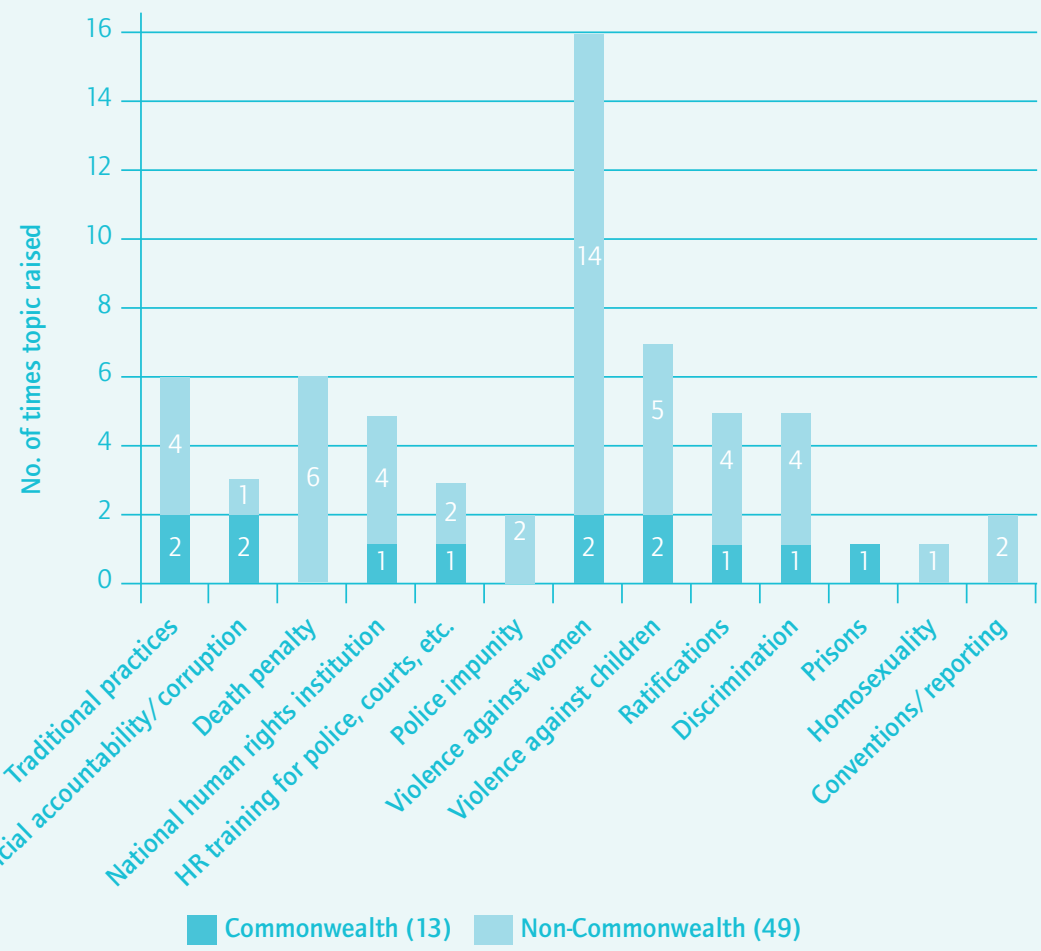




\section{Graph 5. Pakistan}

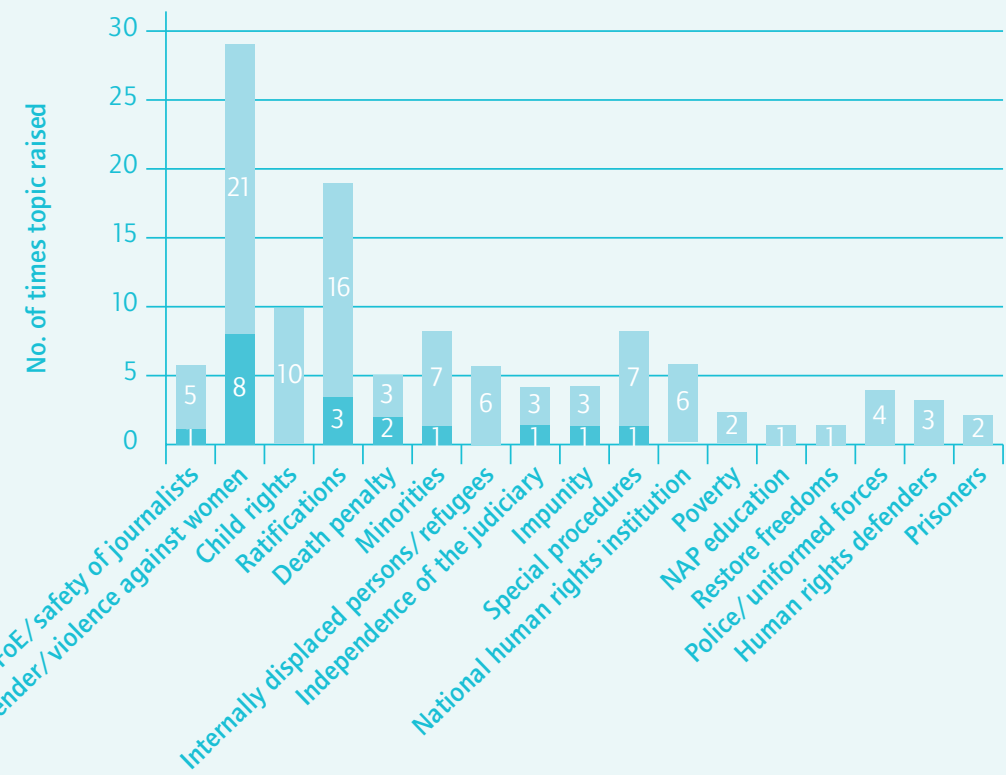

Commonwealth (18) Non-Commonwealth (100) 
Graph 6. Zambia

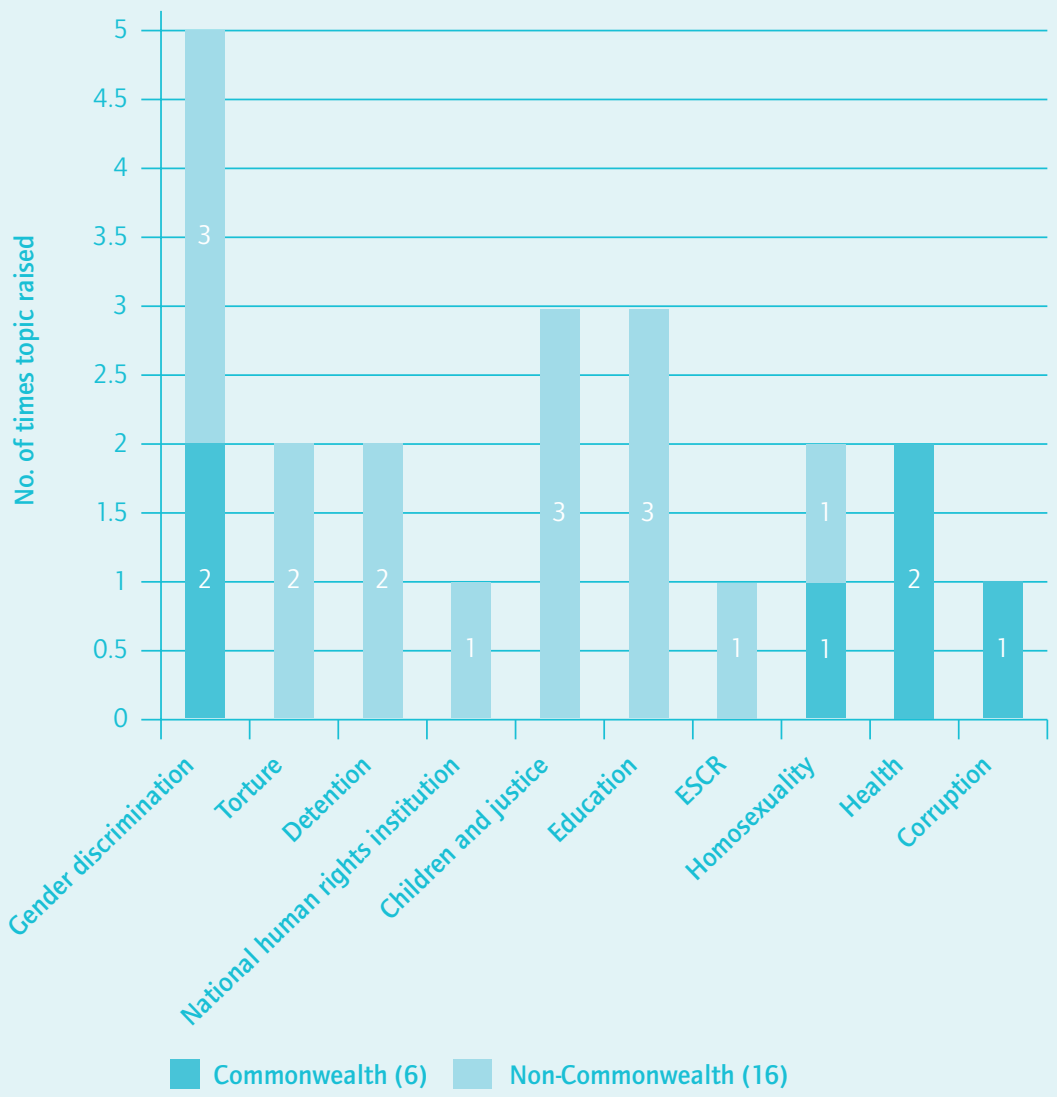




\section{Graph 7. Sri Lanka}

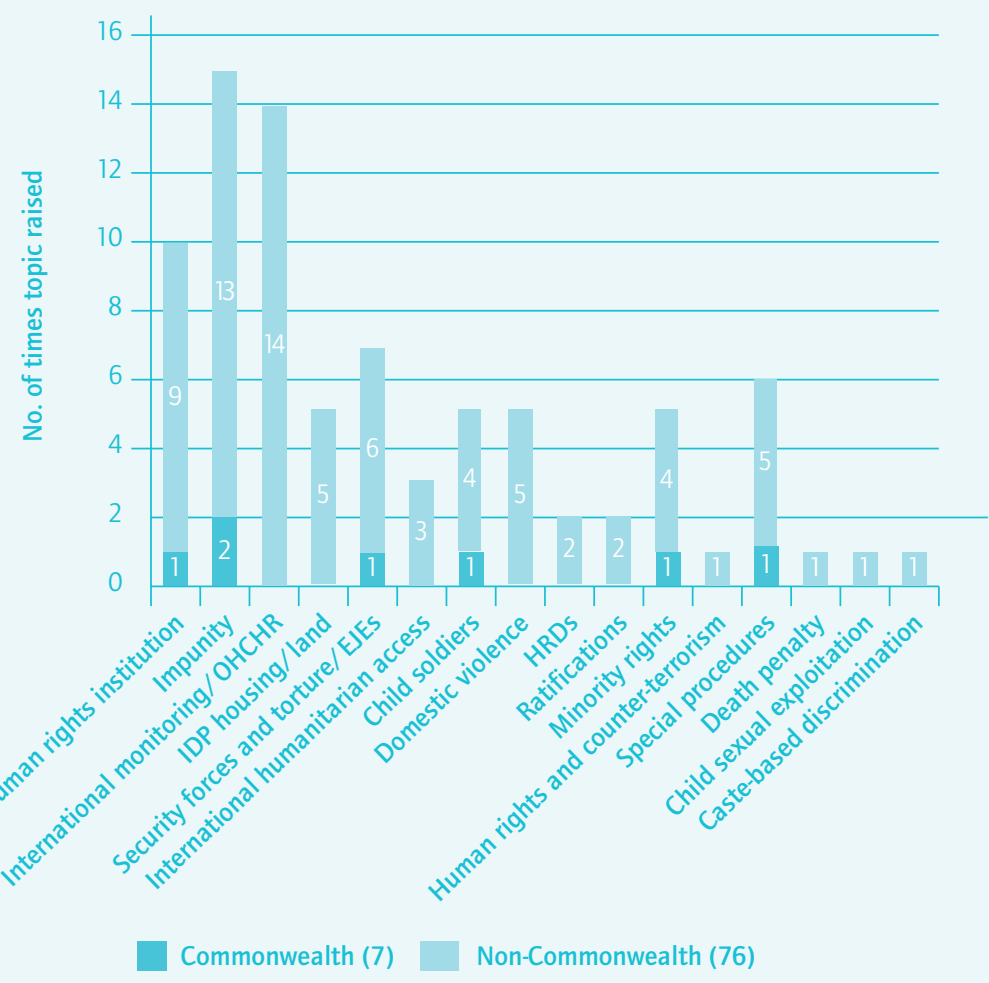




\section{Graph 8. Tonga}

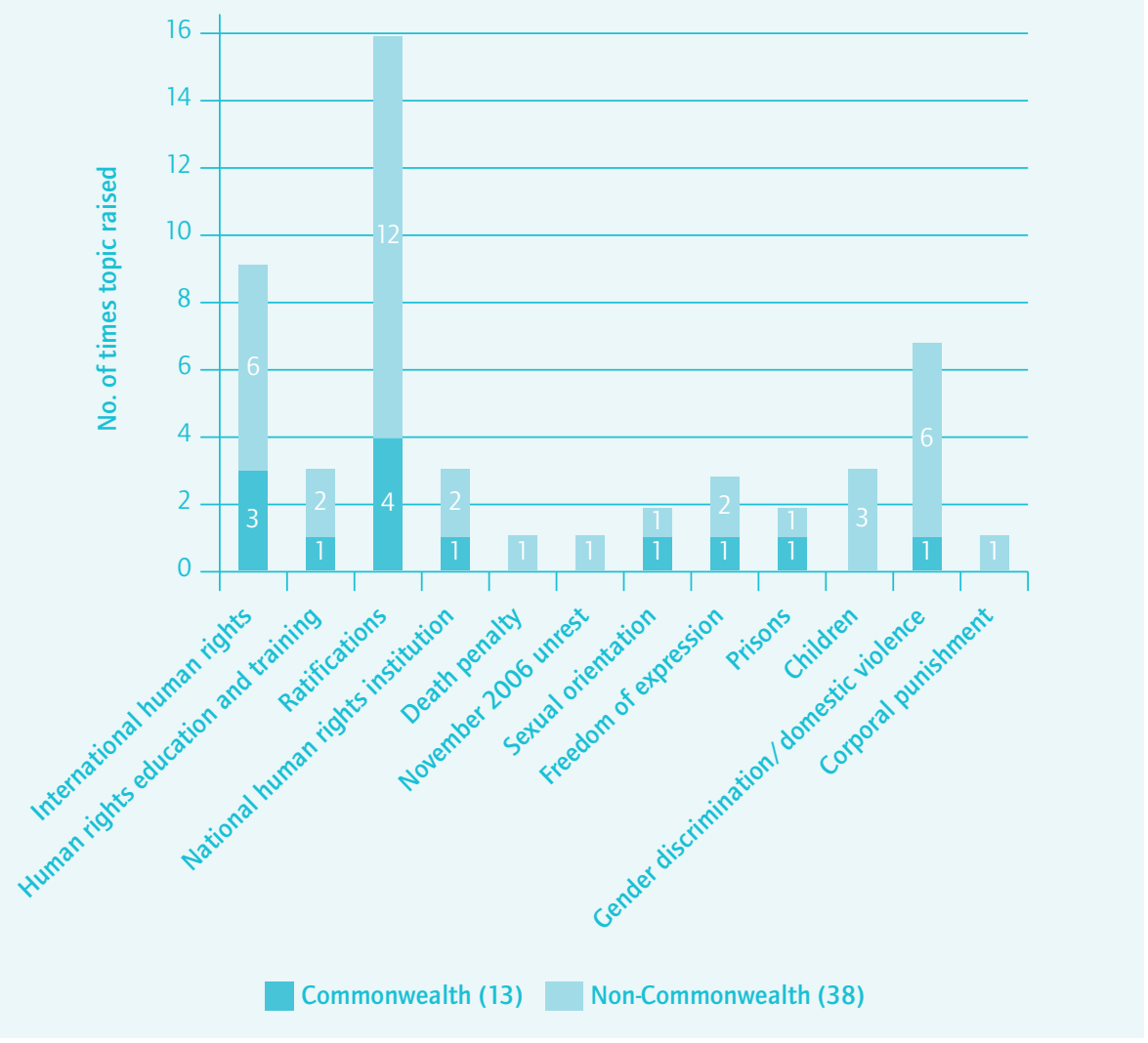




\section{Graph 9. Botswana}

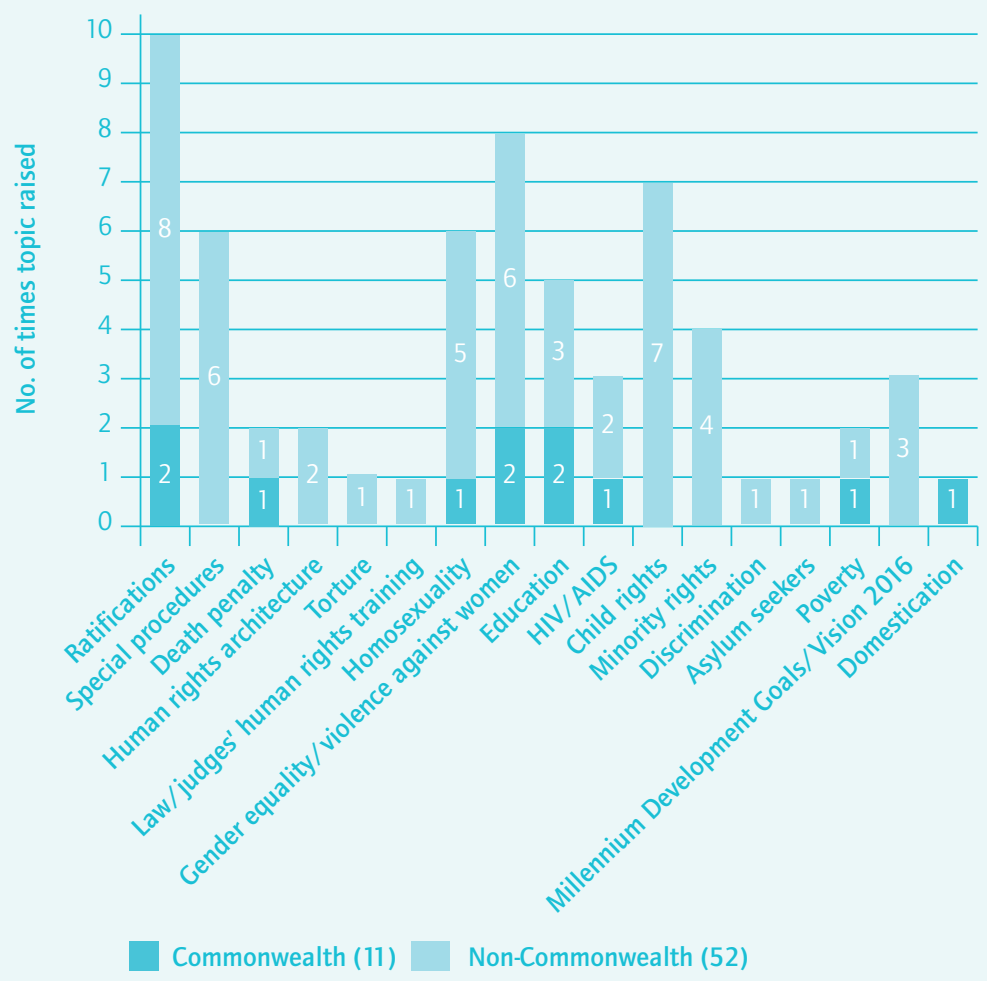


Graph 10. The Bahamas

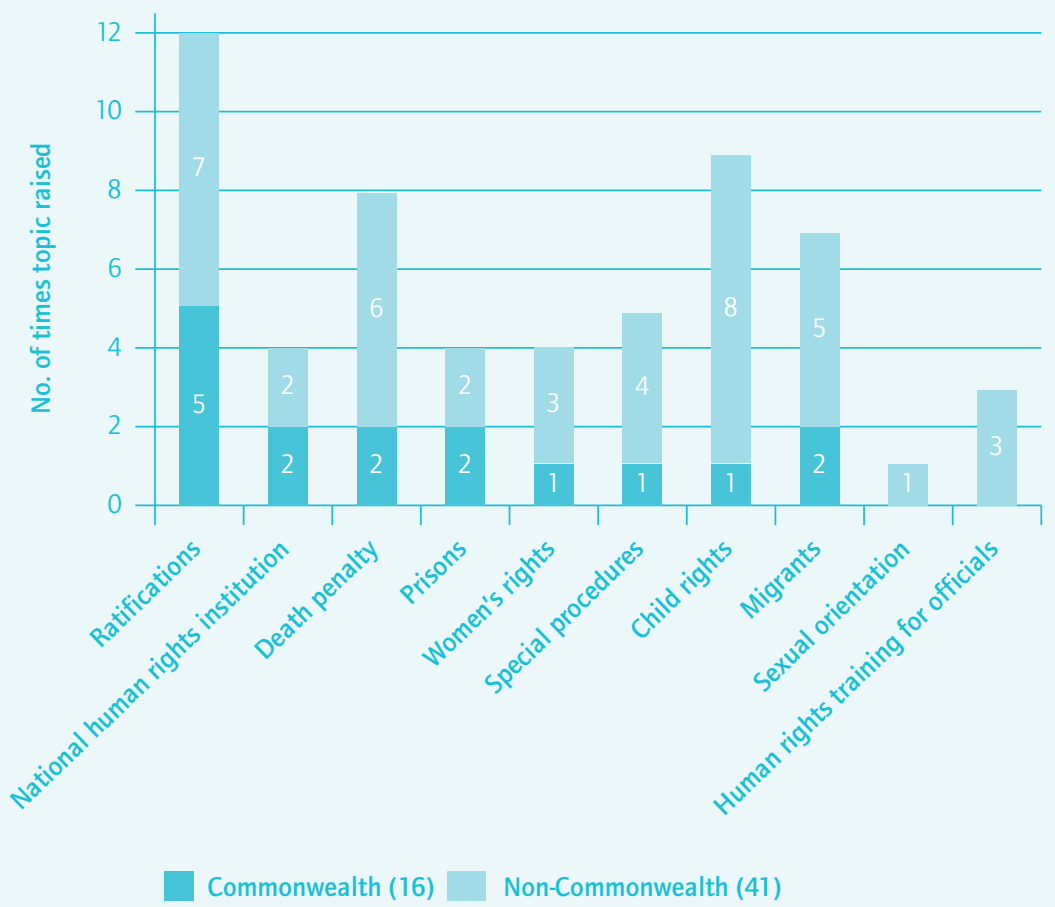




\section{Graph 11. Barbados}

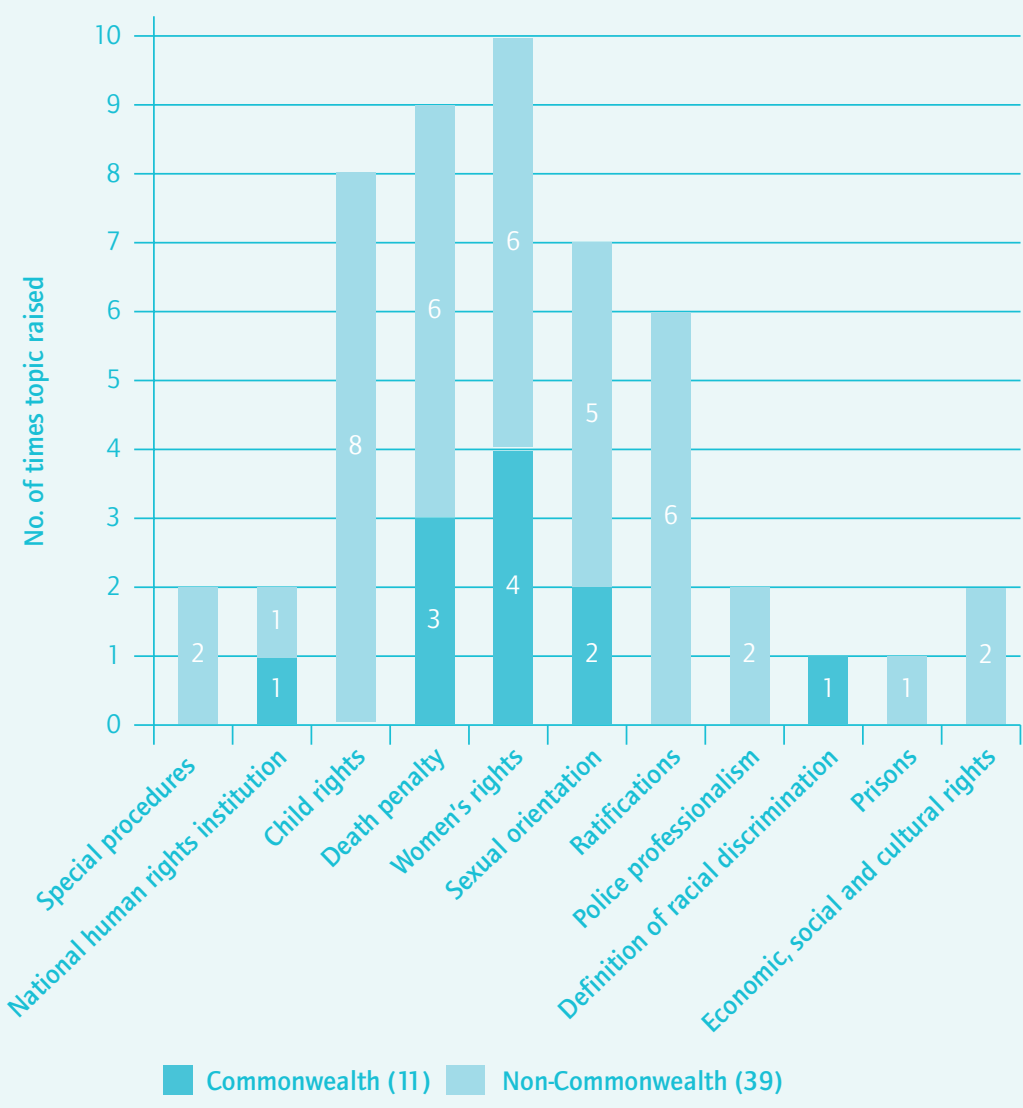


Graph 12. Tuvalu

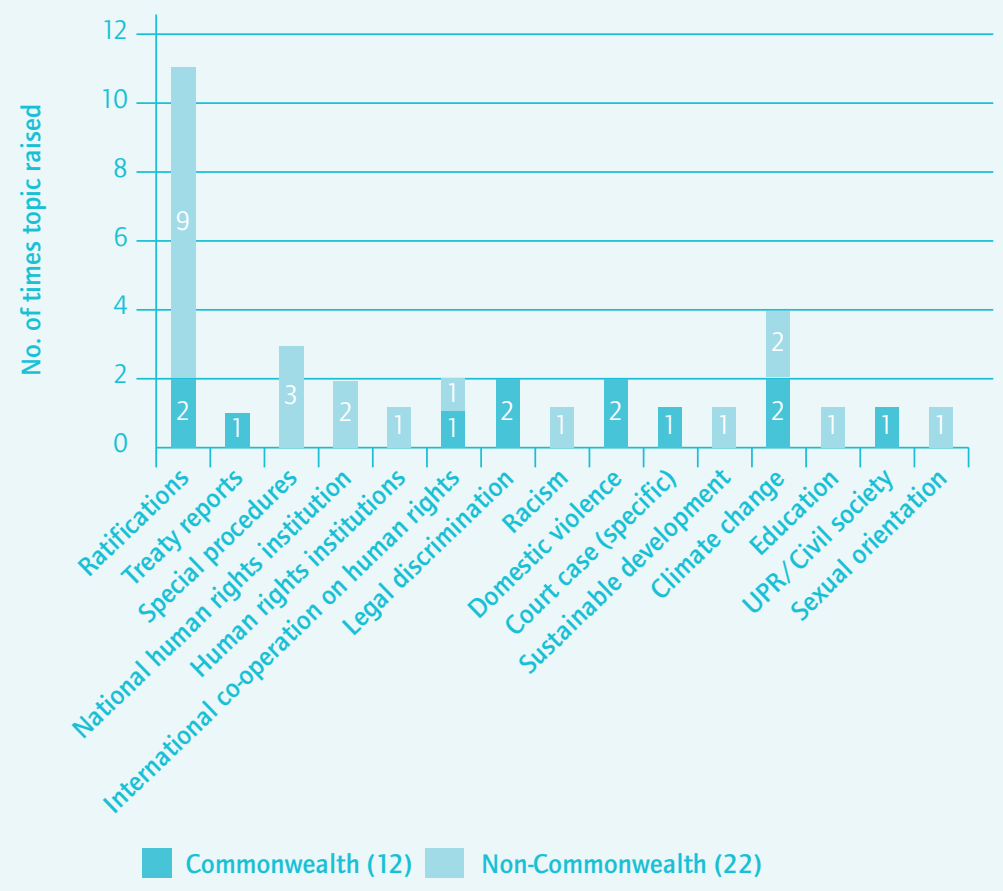


Graph 13. Themes raised most often, 2008

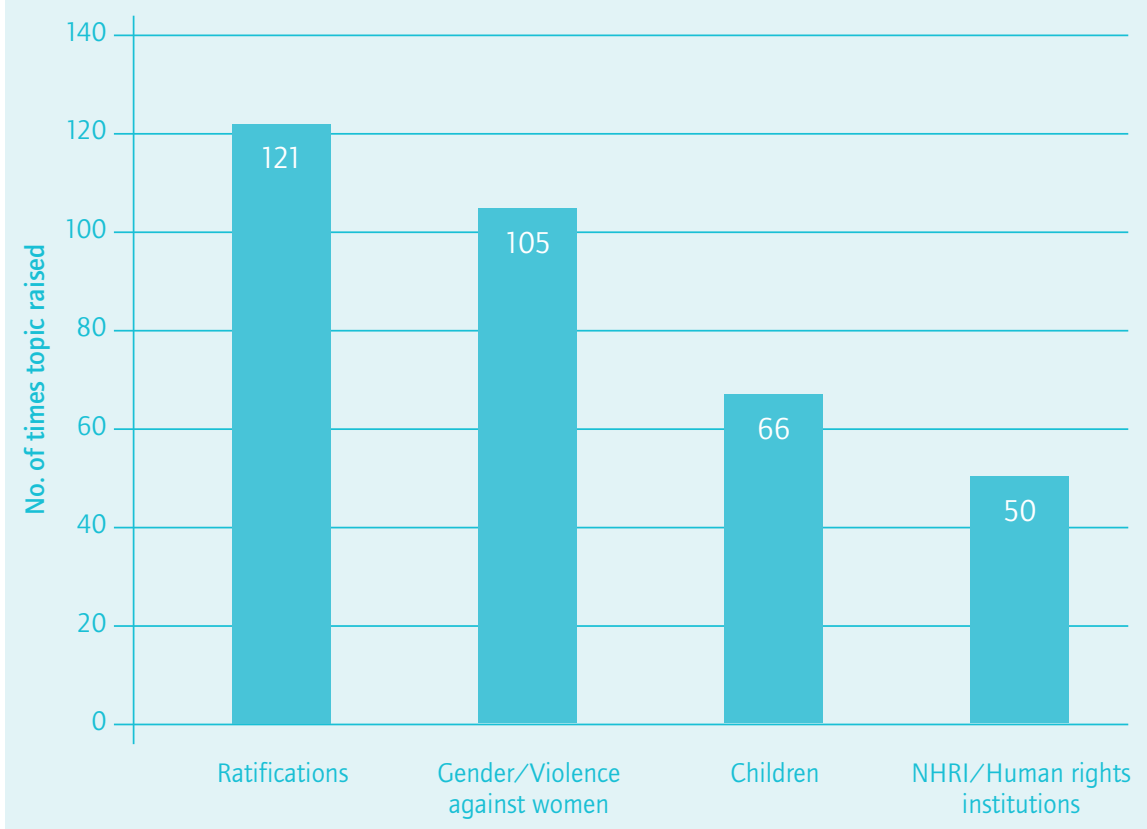




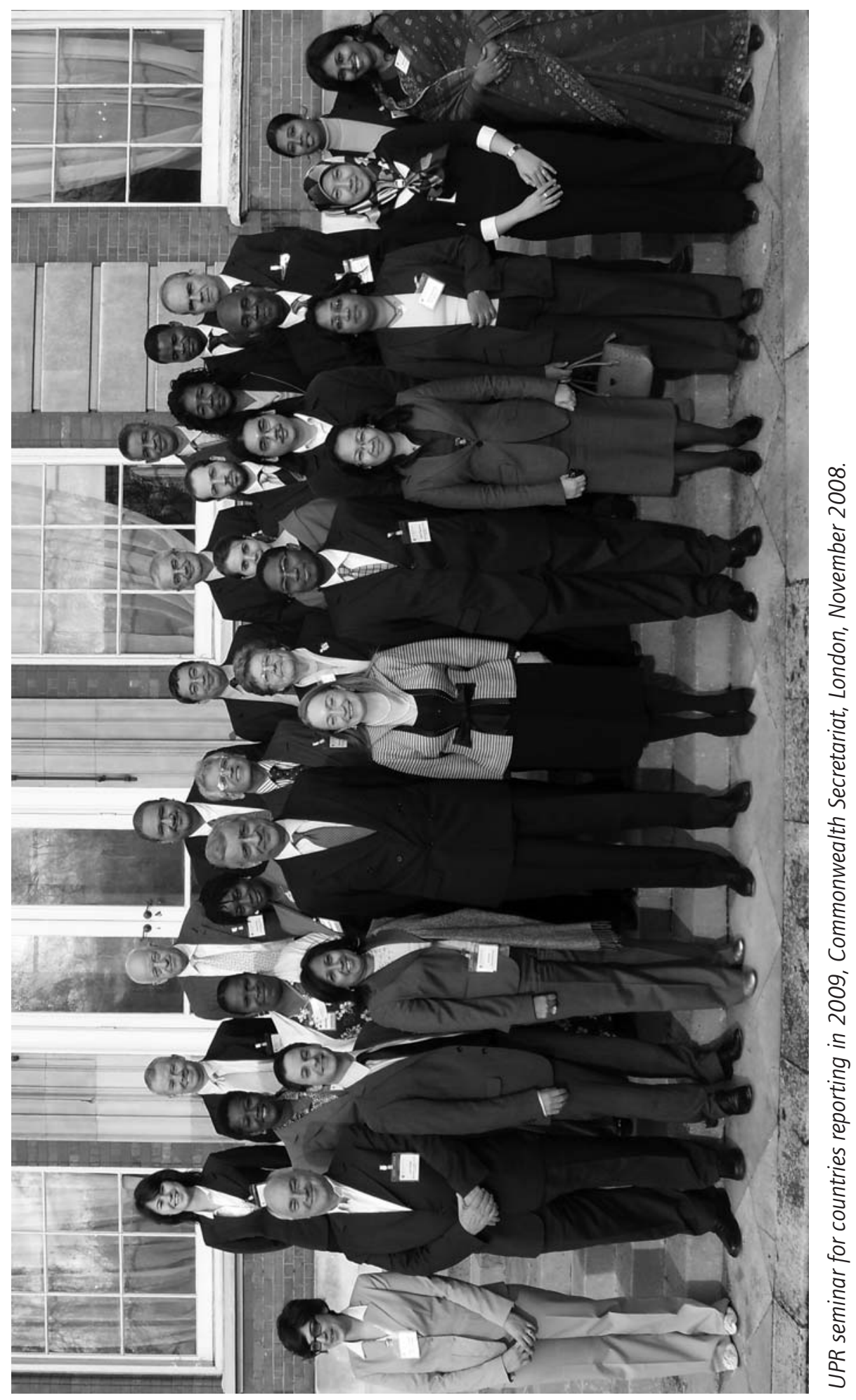

